\title{
3D Physical Modelling Study of Shield-Strata Interaction under Roof Dynamic Loading Condition
}

\author{
Shengli Yang $\mathbb{D}^{1,2}$ Hao Yue $\mathbb{D}^{1,},{ }^{1,2}$ Gaofeng Song $\mathbb{D}^{3}{ }^{3}$ Junjie Wang $\mathbb{D}^{1,2}$ Yanyao Ma $\mathbb{D}^{1,2}$ \\ and Fengqi Liu ${ }^{10}{ }^{1,2}$ \\ ${ }^{1}$ School of Energy and Mining Engineering, China University of Mining and Technology, Beijing 100083, China \\ ${ }^{2}$ Research Centre of Top-Coal Caving Mining in Coal Mining Industry, Beijing 100083, China \\ ${ }^{3}$ School of Civil Engineering, North China University of Technology, Beijing 100144, China \\ Correspondence should be addressed to Gaofeng Song; song.gaofeng@ncut.edu.cn
}

Received 14 October 2020; Revised 4 November 2020; Accepted 29 January 2021; Published 10 February 2021

Academic Editor: Xavier Chiementin

Copyright ( $\odot 2021$ Shengli Yang et al. This is an open access article distributed under the Creative Commons Attribution License, which permits unrestricted use, distribution, and reproduction in any medium, provided the original work is properly cited.

The dynamic hazards in the open face area caused by the impact load of the massive strong roof become increasingly severe with the increase in the cutting height of the longwall face and its depth of cover. Understanding the strata-shield interaction under the dynamic impact loading condition may relieve the dynamic hazards. In this paper, a 3D physical modelling platform is developed to study the interaction between the roof strata and the longwall shield under the dynamic impact load conditions. A steel plate is dropped to the coal face wall at a certain height above the immediate roof to simulate the free fall of the main roof and the dynamic impact loading environment. The occurrence of major roof falls is modelled at different height above the model and at different positions relative to the longwall faceline. The large-cutting-height and top-coal-caving mining methods are modelled in the study to include the nature of the immediate roof. The results show that the level of face and roof failures depends on the magnitude of the dynamic impact load. The position and height of the roof fall have an important influence to the stability of the roof and face. The pressures on the shield and the solid coal face are relieved for the top-coal-caving face as compared to the large-cuttingheight face.

\section{Introduction and Background}

In China, coal is still and will remain the most important energy source for a long period of time $[1,2]$. The main method for coal recovering is the longwall mining method, which has an edge over the room and pillar method in terms of the coal recovery, production, and productivity $[3,4]$. The ground control problems in the open face area is mostly observed as the dynamic fall of the massive strong main roof, with an impact loading to the longwall shield and the coal face and leading to an excessive closure of shield cylinder and collapse of the longwall face [5-10] (see Figure 1). With the progressive development of the longwall face, the overhang length of the roof in the gob area continues to increase. The first main roof fall occurs when the limit span is reached, causing a dynamic load to the longwall face in the face area. As the roof fall occurs repeatedly during the roof weighting period, the dynamic impact in the face area is also observed periodically. This dynamic load generated by the major roof fall is termed the dynamic load impact in this paper. The occurrence of this problem becomes more frequent when the longwall panel is operating at an extra-large height $[11,12]$. For instance, the thick coal seams of 6-9 m widely found in Shendong, Shanbei, Huanglong, and Xinjiang coal bases in the north and west part of China are recovered by the large-cutting-height longwall mining system. Such seams are typically flat and shallow, above which massive and strong conglomerate channels are occurred. Currently, the $8.8 \mathrm{~m}$ single-cut longwall mining method has been successfully practiced in Shanwan mine, Shendong base [13]. As the shallow coal resources being increasingly depleted, coal in a deeper depth of cover is mined, and the issue of dynamic hazards in the open face area has become more intractable. These ground control problems (especially 


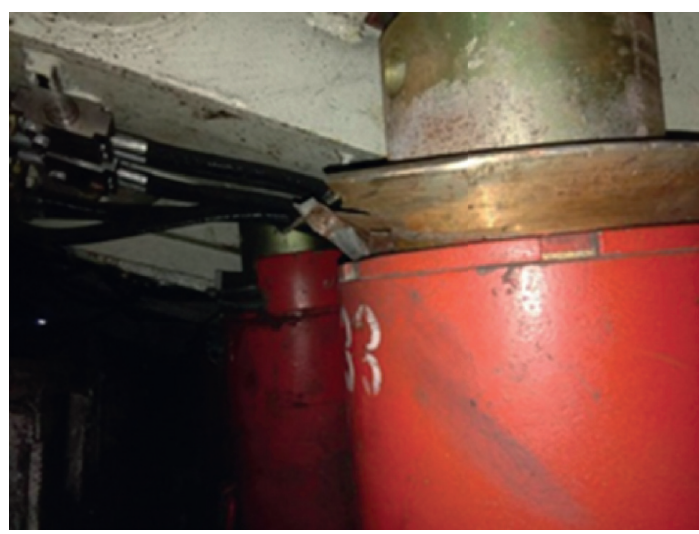

(a)

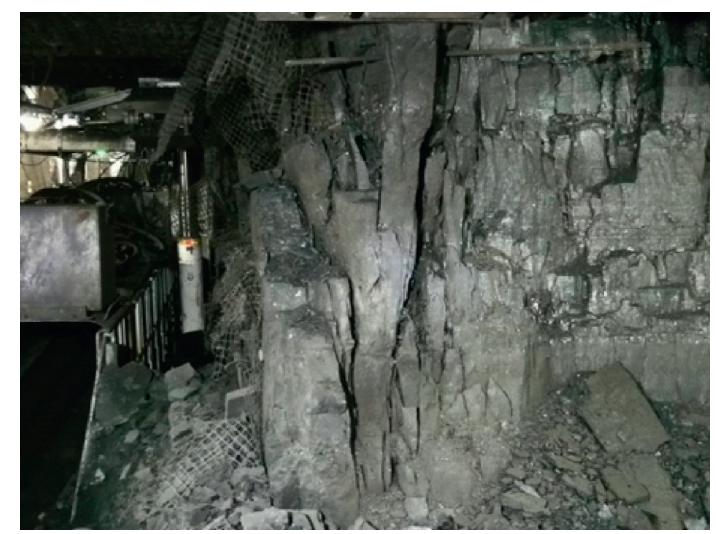

(b)

FIGURE 1: Dynamic load hazards in open face area: (a) shield collapse from roof fall; (b) face failure from excessive roof-to-floor closure.

the dynamic roof movement) may cause loss of operating time, damage of longwall shields, reduction in production and profits, and increased risk of water table contamination.

The collapse of the roof plays an important role in the dynamic hazards in the open face area, and the goal is to reduce if not to control the negative impact of the major roof fall to the longwall shield and the longwall face $[14,15]$. One important factor affecting the level of dynamic roof hazards in the open face area remains the position of roof collapse [16]. If the natural fall of the cantilever roof at periodic roof weighting occurs behind the longwall shield, the face stability might be better off. If the roof falls right above or ahead of the longwall shield, the dynamic hazards are more likely to occur. The magnitude of the impact loading to the longwall face also depends on factors such as the geometry and weight of the main roof, the separation between the main roof and the immediate roof, and the mechanical properties of the longwall shield. In fact, these factors affecting the ground control problems in the open face area can be identified as the geological factors, shield capacity, and technical factors $[17,18]$. Geological factors such as the depth of cover, presence of faults, seam inclination, and mechanical and geometric parameters of the strata are the uncontrolled factors at a specific mine site. The shield capacity, on the contrary, includes the setting load, yielding load, shield size, web width, and tip-to-face distance and is dependent on operators. Efforts have been performed to increase the shield capacity since the introduction of longwall shields [19, 20]. The current most powerful longwall shield in China has increased the cylinder diameter to $600 \mathrm{~mm}$ and the support load to 2,600 t. Technical factors include mining methods, face length and width, previous extraction adjacent to the current longwall panel, and the face advance rate [21].

The shield capacity is considered as one of the most important factors affecting the strata movement. In fact, the key to solve the ground control problem in the open face area lies in improving our understanding on the roof-strata interaction. This interaction is even slightly different for a top-coal-caving longwall face where the roof-strata interaction becomes the coupling between the crashed top coal (rather than the stiffer roof) and the longwall shield [22]. A number of models have been developed to study how the longwall shields interact with the surrounding strata $[23,24]$. The methods include the detached block model, equivalent system stiffness model, immediate roof-main roof coupling model, load cycle analysis, ground response curve, and numerical modelling studies. Physical modelling of roof caving behaviours has also been extensively performed for reproducing the progressive development of strata movement and roof failures [25]. The models have considered the impact loading on shields, extension of caved and fractured zone heights, face failure and shield-strata interactions, acoustic emission signals, configuration of disturbed overburden strata, etc. However, the previous physical models on impact loading were mostly in 2 dimensions. Previous studies have largely improved our understandings on coupling of the shield with surrounding rocks in the face area. However, the shield-strata interaction under dynamic roof loading conditions requires further investigation. This paper attempts to extend the study of roof dynamic movement in 3D from a physical modelling study.

\section{Model Development}

2.1. Similarity Principles and Modelling Rig. The physical modelling test must follow a number of similarity principles to make sure that the physical model behaves in a similar way to the real case (full scale case). According to the principles, physical features of the model should be similar to the real case in terms of geometry, density, and strength so that the measurements in the physical model can be compared with the real case. The similarity coefficients are defined as the ratios of real case parameters including the geometry, density, and strength to the physical model. Based on the mechanical properties of coal measure strata and dimensions of physical modelling rig, the similarity coefficients of geometry, density, and strength are determined as $10,1.7$, and 17 , respectively.

Figure 2 shows the 3D physical modelling rig used in this research. It has an overall dimension of $800 \times 1500 \times 1300 \mathrm{~mm}$ in width, length, and height, respectively. The physical model is constructed in the main 


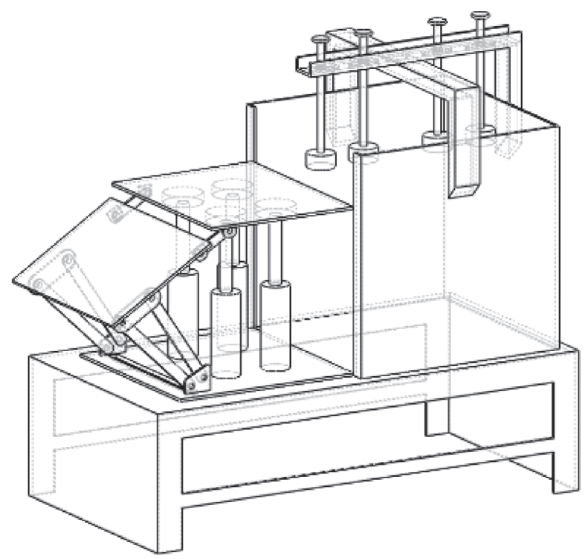

(a)

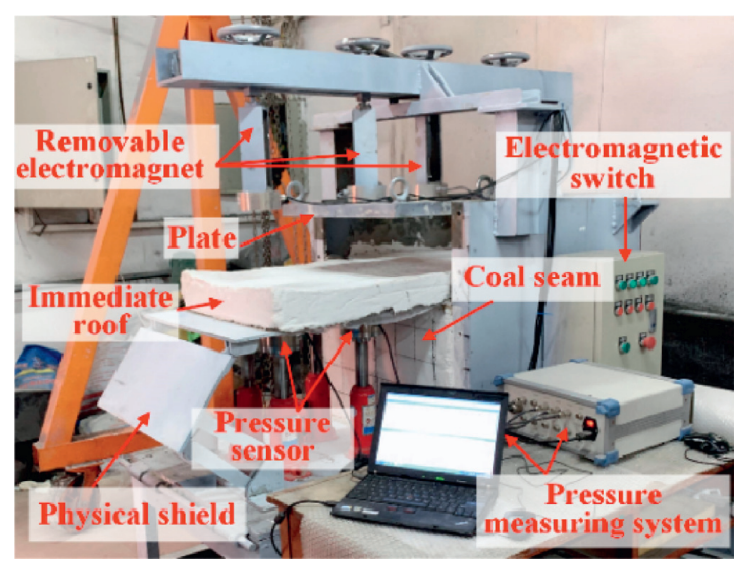

(b)

FIGURE 2: The 3D physical modelling rig for roof dynamic loading test: (a) schematic and (b) constructed model with the measuring system.

steel frame with a dimension of $800 \times 750 \times 650 \mathrm{~mm}$. A 4-leg physical shield is placed ahead of the coal seam so that the shield-strata interaction can be included in this study. The pressure sensors on hydraulic legs connecting to the measuring system are used to record the cylinder pressures from roof fall. Above the immediate roof is a steel plate attached to a removable electromagnet. The steel plate is a certain displacement from the immediate roof for simulating the bed separation in the field. During the modelling test, the steel plate is dropped to the immediate roof for modelling the impact loading conditions in the open face area. The fall of the steel plate is controlled by the electromagnetic switch. Figure 2(a) is a schematic picture of the experiment. The final model with placement of measuring system is given in Figure 2(b).

\subsection{Model Construction and Modelling Procedure.} Geo-mechanical modelling materials for constructing the physical model are carefully selected in this study. Two models are constructed for simulating two of the most important thick coal seam mining methods, i.e., the largecutting-height and top-coal-caving mining method (see Figure 3). The large-cutting-height model consists of the $35 \mathrm{~mm}$ coal seam and $30 \mathrm{~mm}$ immediate roof (Figure 3(a)). The construction materials for modelling the coal seam is a mixture of sand, lime, and gypsum with a proportion of 75 : $4: 4$ by weight, while the immediate roof is composed of sand, lime, gypsum, and cement at a proportion of $45: 45: 4$ : 4. The proportion of the components is determined through a trial and error process to ensure that the constructed physical strata have the proper physio-mechanical properties. The solid materials are fully mixed before the addition of water to ensure an overall homogeneity and isotropy. The mixtures are then placed in the modelling steel frame and compacted to the designed height. The physical model is constructed layer by layer to ensure the overall strength and height of the model. The top-coal-caving model, however, consists of the $35 \mathrm{~mm}$ coal seam and $30 \mathrm{~mm}$ loose top coal (see Figure 3(b)). The loose top coal layer is also shown in the top view in Figure 3(b). The coal seam has the same composition of construction materials with the large-cutting-height model, and the loose top coal layer consists of selected $6-8 \mathrm{~cm}$ coal blocks.

Considering the feasibility and simplification of the physical test, the main roof is modelled using a $100 \mathrm{~kg}$ steel plate, which is attached to the beam on the physical modelling rig by an electromagnet. The steel plate is a certain distance above the immediate roof/top coal mass and falls to the immediate roof upon power off of the electromagnetic switch, for simulating the bed separation and the dynamic roof fall. Accordingly, the impact load on the front and rear hydraulic legs and the deformation of face are recorded. On the contrary, the field observation reveals that the main roof typically fractures ahead of, above, or behind the faceline. Roof fall therefore may occur at different positions relative to faceline and lead to significantly different impacts on the face and shield performance. To cover the possible roof fracturing positions, the front edge (pointing to the solid coal side) of the main roof (steel plate) is placed at different lines, for simulating the roof breakage at $10 \mathrm{~cm}$ behind the faceline (Line 1), right above the faceline position (Line 2), and $10 \mathrm{~cm}, 20 \mathrm{~cm}$, and $30 \mathrm{~cm}$ ahead of faceline (Line 3, Line 4, and Line 5). The free fall motion of the main roof is performed at different heights from $0.5-4.0 \mathrm{~cm}$ at an interval of $0.5 \mathrm{~cm}$ above the immediate roof/top coal mass. The impact pressures of the hydraulic legs reacting at the dynamic roof fall are recorded using the pressure measuring system. The roof fall at a particular position and height is repeated 3 times to reach an average value on the leg pressures. The physical shield maintains the same setting pressure before each dynamic roof fall.

In this paper, a dynamic load coefficient $(K)$ is defined as the ratio of the dynamic load on hydraulic legs over the weight of immediate roof and main roof (see Equation (1)). The dimensionless coefficient is used to assess the level and intensity of dynamic roof fall:

$$
K=\frac{F}{m_{1} g+m_{2} g},
$$

where $F$ is the impact load on the hydraulic legs obtained from the pressure measuring system in $\mathrm{kN}, m_{1}$ is the mass of 


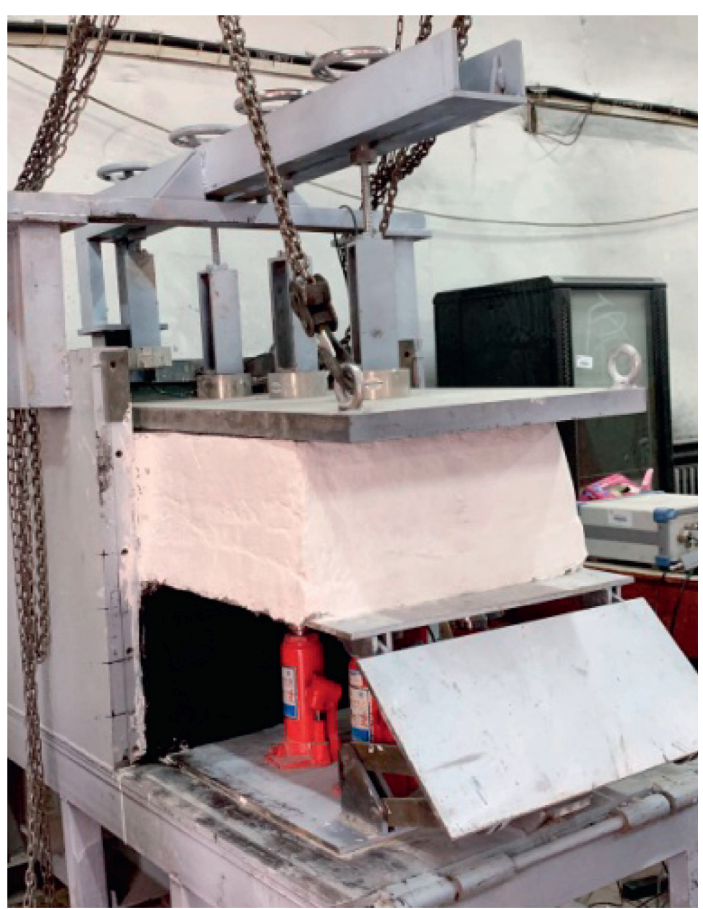

(a)

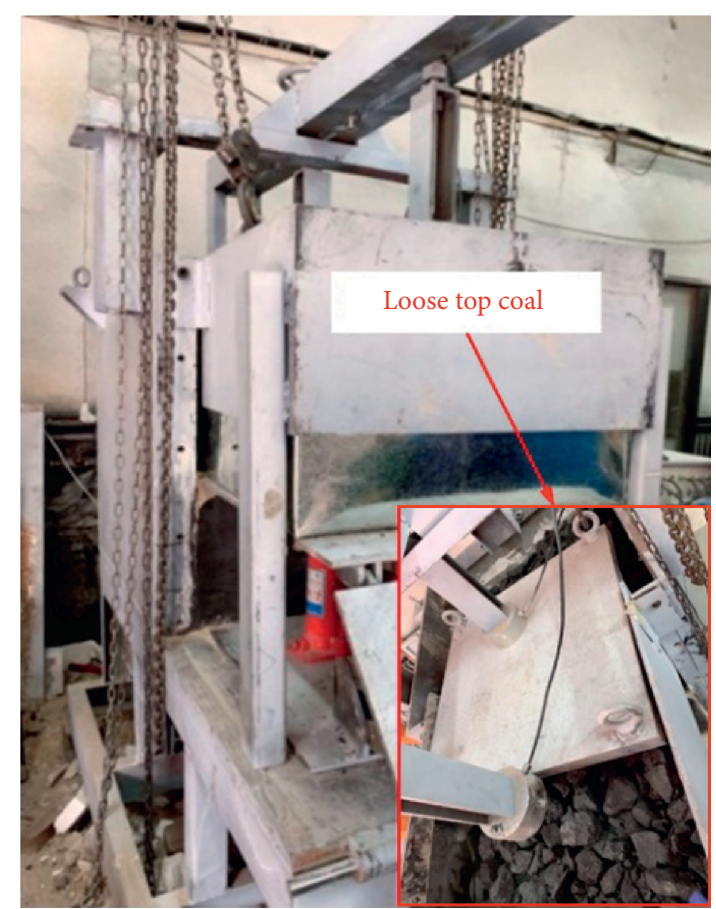

(b)

FIgURE 3: The constructed physical models: (a) large-cutting-height model; (b) top-coal-caving model.

the immediate roof in $\mathrm{kg}, \mathrm{g}$ is the acceleration of gravity in $\mathrm{m} / \mathrm{s}$ [2], and $m_{2}$ is the mass of the steel plate in $\mathrm{kg}$.

For the top-coal-caving model, the top coal mass functions as a buffer component to partially absorb the impact energy from roof fall. A buffer coefficient $\left(\eta_{k}\right)$ is further defined for describing the ability of energy absorbing for the top coal mass and given as

$$
\eta_{k}=\frac{F_{1}-F_{2}}{F_{1}},
$$

where $F_{1}$ is the shield impact load on large-cutting-height model in $\mathrm{kN}$, while $F_{2}$ is the impact load on shield after the placement of top coal mass.

\section{Results and Analysis}

3.1. Development of Roof and Face Failures. Figure 4 shows the roof and face failures under the dynamic roof impact loading conditions. The initial buckling of the face for the large-cutting-height model is given in Figure 4(a), indicating the horizontal movement of coal face wall. The massive face fall occurs after a few impact loads from the main roof (see Figure $4(\mathrm{~b}))$. The face fall extends $5-10 \mathrm{~cm}$ deeper into the solid coal face and covers the entire area of the face in the physical model. The top view in Figure 4(c) shows the failure of the immediate roof along the faceline under the impact load of the main roof. Typically, if the main roof falls from a higher position above the immediate roof or the weight of the free fall main roof is larger, then the level of the immediate roof and face failure is larger. The failure of the roof and the face depends on the magnitude of the dynamic impact load and the separation between the main roof and the immediate roof. In fact, the separation of the strata plays a vital role to the level of the impact loading at the face area. Therefore, one of the possible measures to relieve the impact load of the main roof is to increase the shield capacity or the setting load, thus to reduce the likelihood of roof separation.

3.2. Development of Dynamic Load Coefficient. Figure 5 plots the development of dynamic load coefficients at different positions and height of roof fall for the large-cutting-height and top-coal-caving models, respectively. Both the roof fall positions relative to faceline and the roof fall height have a significant influence on shield leg pressures. Generally, the dynamic load coefficient increases with the roof fall height, indicating that a larger roof separation may generate greater pressures on shield hydraulic legs and increase the risk of cylinder damage. At the same roof fall height, however, the dynamic load coefficient is larger when roof fall occurs behind the face above the shield than that when the roof falls ahead of the faceline. This is because the solid coal seam may absorb part of the impact load energy if the main roof falls ahead of the faceline. Hence, when the strong and massive conglomerate channels are found sitting above the seam, roof preblasting or fracturing ahead of the face or behind the shield is recommended to relieve the roof pressure and protect shields from an iron-bound incident (a sudden full closure of the hydraulic cylinders).

For the top-coal-caving model, the dynamic load is much smaller than the large-cutting-height face, which agrees with the field observation. The maximum dynamic load coefficient is only 2.3 for the top-coal-caving model, 


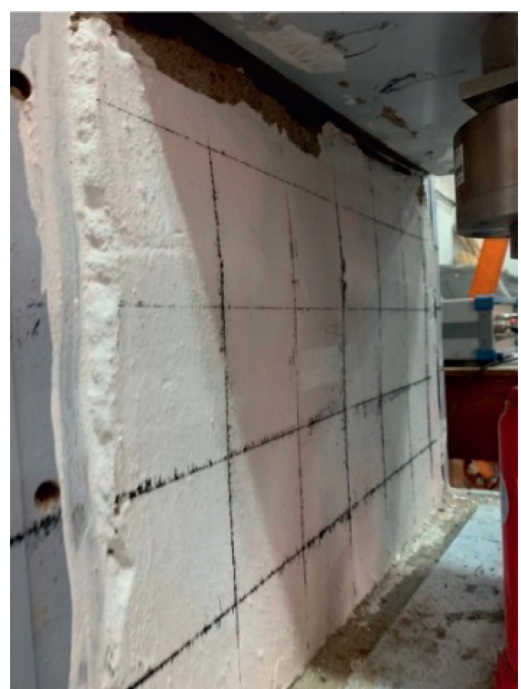

(a)

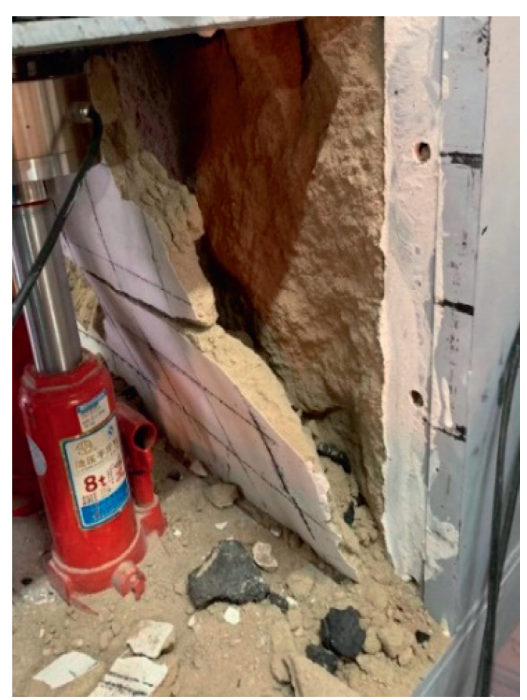

(b)

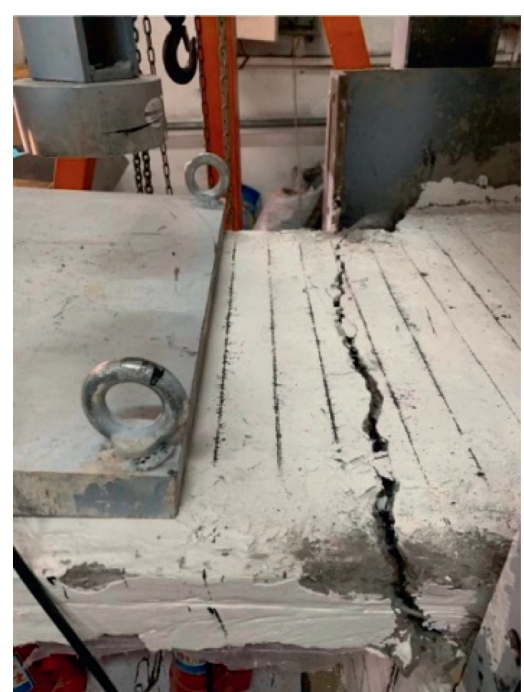

(c)

FIGURE 4: Roof and face failures of the physical models under dynamic roof loading: (a) face buckling; (b) face fall; (c) roof fall.

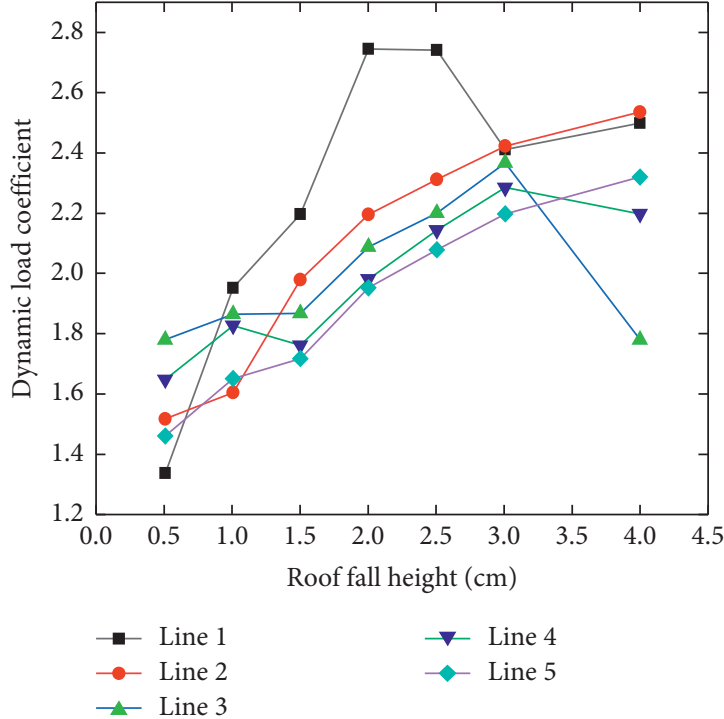

(a)

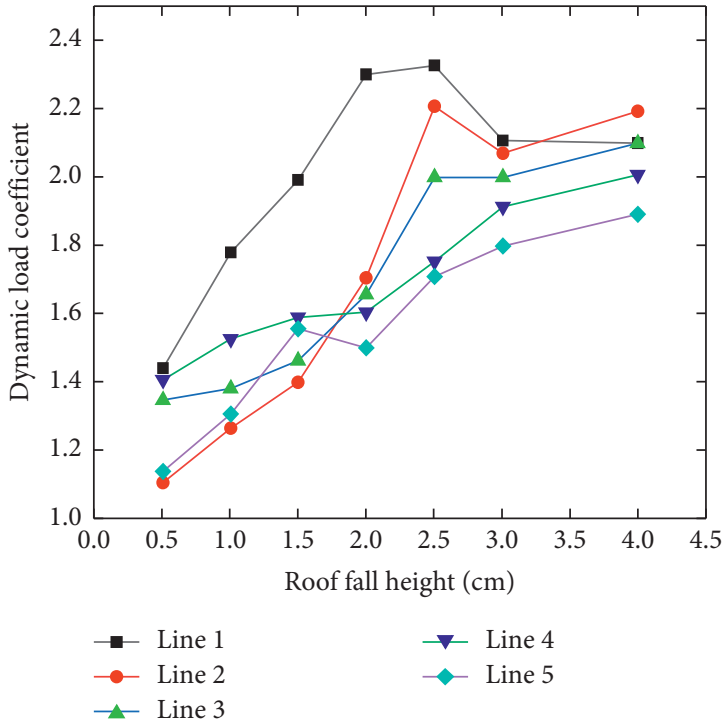

(b)

Figure 5: Dynamic load coefficient at different positions and heights of roof fall: (a) large-cutting-height face; (b) top-coal-caving face.

compared with 2.8 for the large-cutting-height model. The top coal mass between the main roof and shield functions as a shock absorber and benefits the shield performance. Hence, it is speculated that the fragmentation of the top coal or similarly the immediate roof benefits the shield and face stability.

The distribution of shield load on the four hydraulic legs of the shield at different roof fall positions is provided in Figure 6. For Position 1 (P1), the position of roof fall is simulated at $20 \mathrm{~cm}$ ahead of the face; while Position 9 (P9) simulates the fall of main roof at $20 \mathrm{~cm}$ behind the face. The positions of roof fall are designed at a $5 \mathrm{~cm}$ interval; therefore, $\mathrm{P} 5$ represents the roof fall position right above the faceline. Once again, it is seen from the total shield load that the shield sustains more roof loads if the fall of roof occurs behind the faceline, and the top-coal-caving longwall face shows relieved load on the shield as compared to the largecutting-height model. The distribution of load on different shield legs, however, does not present a clear rule.

3.3. Development of Buffer Coefficient at Different Roof Fall Positions. The distribution of buffer coefficient on shield legs at different roof fall positions is given in Figure 7. Note that the roof falls from $15 \mathrm{~cm}$ above the top coal mass in this particular model. The kinetic energy from the free fall of 


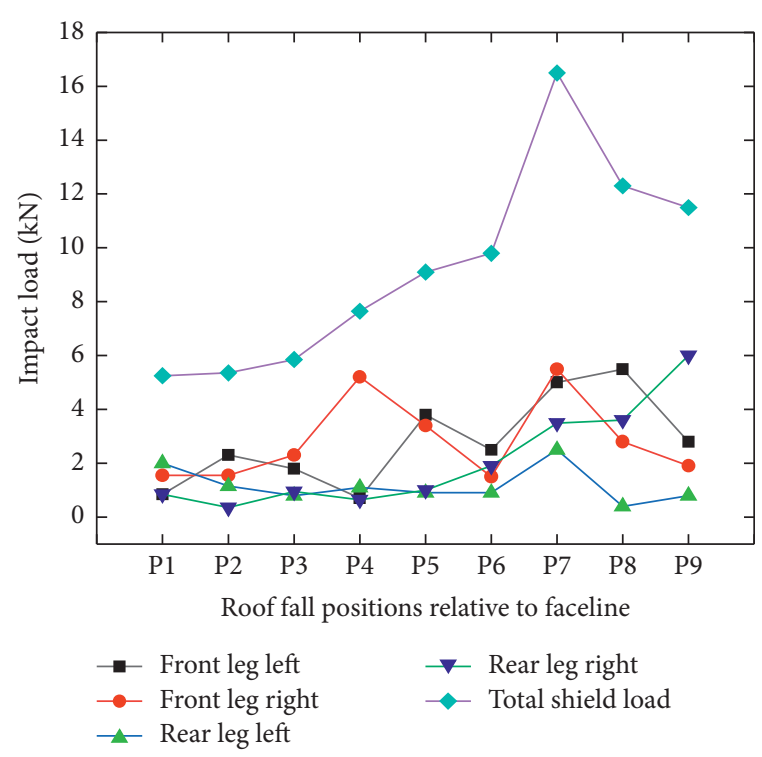

(a)

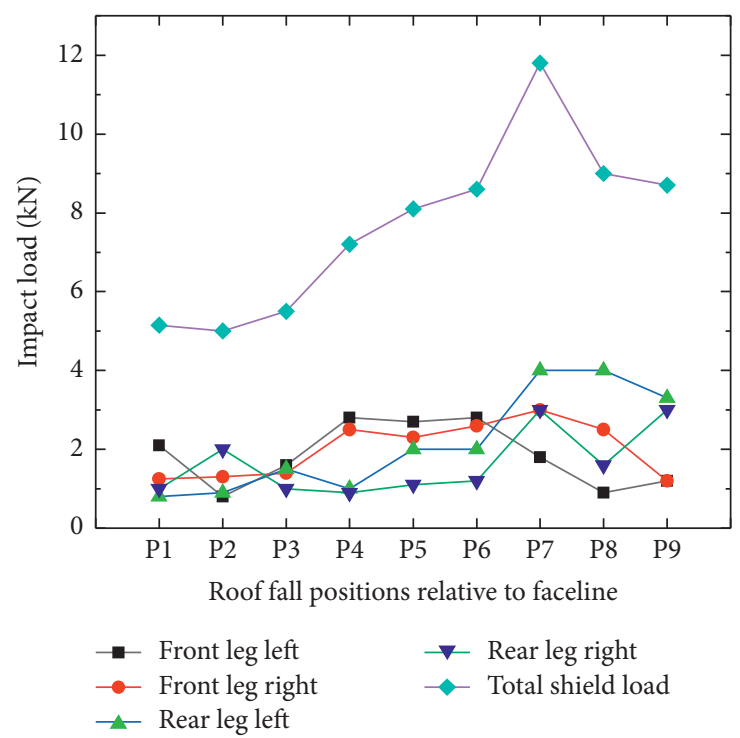

(b)

FIGURE 6: Distribution of dynamic load on shield legs at different roof fall positions: (a) large-cutting-height model; (b) top-coal-caving model.

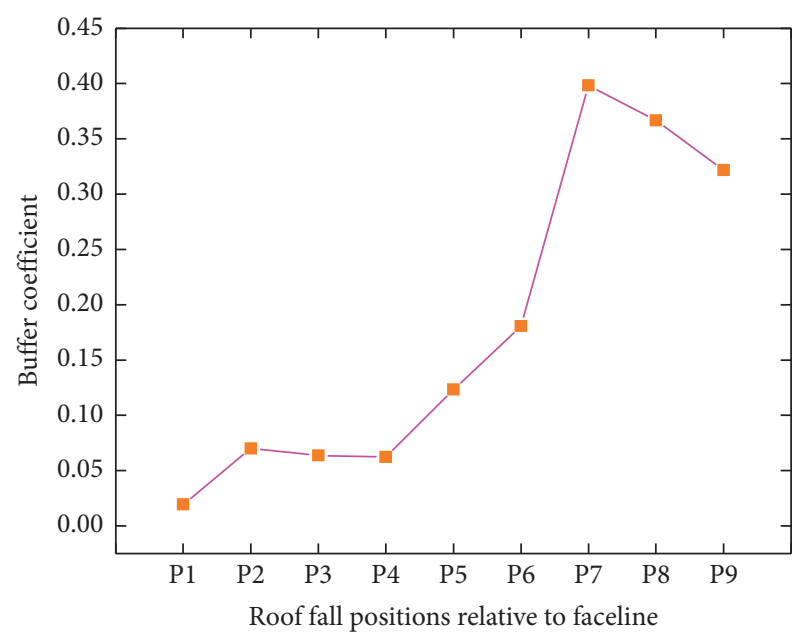

Figure 7: Distribution of buffer coefficient on shield legs at different roof fall positions. Roof fall positions $\mathrm{P}_{1}-\mathrm{P}_{9}$ have the same meaning with Figure 6.

main roof is partially consumed by the collision between the main roof and the top coal blocks, which functions as the buffer component. A smaller buffer coefficient represents that more kinetic energy is absorbed by the top coal mass. It is observed that the buffer coefficients are smaller at roof fall positions ahead of faceline $\left(\mathrm{P}_{1}-\mathrm{P}_{4}\right)$ and are significantly increased when the roof fall occurs behind the faceline $\left(\mathrm{P}_{6}-\mathrm{P}_{9}\right)$.

\section{Summary and Discussion}

In this paper, a 3D physical modelling platform is developed to study the interaction of strata and the longwall shield under the dynamic impact load conditions. A steel plate is used to simulate the main roof and is dropped to the immediate roof for modelling the free fall motion of the roof and the dynamic impact loading environment in the open face area. The major fall of the roof occurs at different heights above the immediate roof and at different positions with respect to the longwall faceline. The longwall faces are modelled as the large-cutting-height face and the top-coal-caving face in this study to include the nature of the immediate roof. The development of the roof and face failures, the dynamic load coefficient, and the buffer coefficient are analysed under different roof fall conditions. Important findings of this study are given below:

(1) The longwall face buckles and then collapses under the roof impact loads. The immediate roof fractures along the faceline. The level of face and roof failures depends on the magnitude of the dynamic impact load.

(2) The position of the roof fall relative to the longwall faceline also has an important influence to the stability of the roof and face. The coal face and the shield sustain a larger load if the major roof falls occur behind rather than ahead of the faceline.

(3) The load on the shield legs and the face also increases with the height of roof fall or equivalently the separation between the main roof and the immediate roof. Increased shield capacity and setting load may reduce this separation.

(4) The pressures on the shield and the solid coal face are relieved for the top coal-caving face as compared to the large-cutting-height face, which is due to the presence of the crushed coal blocks that function as the buffer component to absorb the impact load energy from the collapse of main roof. 


\section{Data Availability}

The data used to support the findings of this study are included within the article.

\section{Conflicts of Interest}

The authors declare that they have no conflicts of interest.

\section{Acknowledgments}

This paper was supported by the National Natural Science Foundation of China (51974320 and 52004010), Natural Science Foundation of Hebei (E2020402041), and Beijing Natural Science Foundation (2204080).

\section{References}

[1] British Petroleum, BP Statistical Review of World Energy 2017, British Petroleum, London, UK, 2017.

[2] X. J. Liu and H. B. Luan, "A brief analysis of the circumstances of the current coal industry and its trends in China," International Journal of Mining and Mineral Engineering, vol. 6, no. 5, pp. 87-96, 2015.

[3] G. Song and S. Yang, "Probability and reliability analysis of pillar stability in South Africa," International Journal of Mining Science and Technology, vol. 28, no. 4, pp. 715-719, 2018.

[4] J. C. Wang, Theory and Technology of Thick Seam Mining, Metallurgy Industry Press, pp. 15-25, Beijing, China, 2009.

[5] G. Song, Y. P. Chugh, and J. Wang, "A numerical modelling study of longwall face stability in mining thick coal seams in China," International Journal of Mining and Mineral Engineering, vol. 8, no. 1, pp. 35-55, 2017.

[6] J. C. Wang, "Mechanism of the rib spalling and the controlling in the very soft coal seam," Journal of China Coal Society, vol. 32, no. 8, pp. 785-788, 2007.

[7] J. C. Wang, S. L. Yang, Y. Li et al., "A dynamic method to determine the supports capacity in long wall coal mining," International Journal of Mining, Reclamation and Environment, vol. 1, no. 1, pp. 1-14, 2014.

[8] J. C. Wang and Z. H. Wang, "Impact effect of dynamic load induced by roof in high-intensity mining face," Chinese Journal of Rock Mechanics and Engineering, vol. 34, no. 2, pp. 3987-3997, 2015.

[9] G. Song and Y. P. Chugh, "3D analysis of longwall face stability in thick coal seams," Journal of the Southern African Institute of Mining and Metallurgy, vol. 118, no. 2, pp. 131-142, 2018.

[10] Y. S. Pan, X. F. Lv, and Z. H. Li, "Experimental study of dynamic failure process of roadway under high velocity impact loading," Rock and Soil Mechanics, vol. 32, no. 5, pp. 1281-1286, 2011.

[11] G. F. Wang, Y. H. Pang, M. Z. Li et al., "Hydraulic support and coal wall coupling relationship in ultra large height mining face," Journal of China Coal Society, vol. 42, no. 2, pp. 518-526, 2017.

[12] G. Wang and Y. Pang, "Surrounding rock control theory and longwall mining technology innovation," International Journal of Coal Science \& Technology, vol. 4, no. 4, pp. 301-309, 2017.

[13] G. F. Wang, X. Y. Li, C. C. Zhang et al., "Research and development and application of set equipment of $8 \mathrm{~m}$ large mining height fully-mechanized face," Coal Science and Technology, vol. 45, no. 11, pp. 1-8, 2017.

[14] N. J. Ma, X. D. Zhao, Z. Q. Zhao et al., "Stability analysis and control technology of mine road way roof in deep mining," Journal of China Coal Society, vol. 40, no. 10, pp. 2287-2295, 2015.

[15] S. L. Wu and S. L. Liu, "Study on roof movement law and powered support-surrounding rook relationship of fullymechanized top coal caving mining face," Coal Science and Technology, vol. 44, no. 2, pp. 104-108, 2016.

[16] Z. L. Li, Research on the Overlying Strata Breakage Mechanismand the Relationship between Support and Surrounding Stratain Shallow-uried and Thin Bedrock Working Face, China Coal Research Institute, pp. 23-27, Beijing, China, 2014.

[17] A. M. Quillan, I. Canbulat, D. Payne et al., "New risk assessment methodology for coal mine excavated slopes," International Journal of Mining Science and Technology, vol. 28, no. 4 , pp. 583-592, 2018.

[18] M. Christopher, "Science of empirical design in mining ground control," International Journal of Mining Science and Technology, vol. 26, no. 3, pp. 461-470, 2016.

[19] G. Song, K. Ding, and D. Kong, "Assessing longwall shieldstrata interaction using a physical model," Quarterly Journal of Engineering Geology and Hydrogeology, vol. 52, no. 4, pp. 536-546, 2019.

[20] D.-Z. Kong, Z.-B. Cheng, and S.-S. Zheng, "Study on the failure mechanism and stability control measures in a largecutting-height coal mining face with a deep-buried seam," Bulletin of Engineering Geology and the Environment, vol. 78, no. 8, pp. 6143-6157, 2019.

[21] G. Song, Z. Wang, and K. Ding, "Evaluation of the face advance rate on ground control in the open face area associated with mining operations in Western China," Journal of Geophysics and Engineering, vol. 17, no. 2, pp. 390-398, 2020.

[22] S. L. Yang, Z. X. Li, W. J. Wei et al., "Experimental study on the influence of loose top coal mining on the relationship between support and surrounding rock," Journal of China Coal Society, vol. 42, no. 10, pp. 2511-2517, 2017.

[23] G. F. Song, Z. W. Wang, and X. Y. Zhong, "Dynamic impact mechanism of hard roof strata and coupling mechanism of constrain-convergence between support and surrounding rock," Journal of Mining and Safety Engineering, vol. 37, no. 5, pp. 951-959, 2020.

[24] S. L. Yang, G. F. Song, and D. Z. Kong, "An evaluation of longwall face stability in thick coal seams through a basic understanding of shield-strata interaction," Journal of Geophysics and Engineering, vol. 16, no. 2, pp. 125-135, 2019.

[25] G. Song and S. Yang, "Investigation into strata behaviour and fractured zone height in a high-seam longwall coal mine," Journal of the Southern African Institute of Mining and Metallurgy, vol. 115, no. 8, pp. 781-788, 2015. 